\title{
EDITORIALS
}

\section{In This Issue: Challenges of Managing Multimorbidity}

\author{
Kurt C. Stange, $M D, P b D$, Editor
}

Ann Fam Med 2012;10:2-3. doi:10.1370/afm.1354.

$\mathrm{T}$ his issue of the Annals features 3 research studies $^{1-3}$ and an editorial ${ }^{4}$ that advance understanding of providing integrated care for people with multiple health conditions. The next issue of the Annals will continue this theme with articles relating to the methodology for investigating and managing multimorbidity. Multimorbidity is becoming the rule rather than the exception for patients seen in primary care ${ }^{5,6}$ as the population ages. One-disease-at-a-time research, quality improvement measures, and interventions ${ }^{7}$ risk fostering further fragmentation of health care. ${ }^{8}$ The Annals is pleased to serve as a forum for the growing consensus that multimorbidity is a central focus for primary care research ${ }^{9,10}$ and that care integration is a central focus for primary care practice and policy advocacy. ${ }^{11,12}$

This issue also contains an executive summary ${ }^{13}$ and link to a longer policy brief ${ }^{14}$ on how care can be coordinated for adults with complex care needs. This work, from the Agency for Healthcare Research \& Quality (AHRQ) and Mathematica Policy Research, is based on case studies of small, independent primary care practices, and is designed to guide policy and strategies for the patient-centered medical home. The complete white paper has been published simultaneously on the AHRQ Web site in a joint effort to make policy-and practice-relevant work quickly and widely available.

The potential for an integrative primary care approach ${ }^{15,16}$ is demonstrated in a study by Jerant and colleagues $^{17}$ that links a nationally representative health care database with the National Death Index. The study finds that the primary care attributes of comprehensiveness, patient-centeredness, and enhanced access are associated with reduced mortality.

Hoebert et al study a policy-level natural experiment ${ }_{1}^{18}$ finding both expected and surprising changes in medication-related diagnoses and treatments after reimbursement restrictions on benzodiazepines.

A clinical study by Mangin and colleagues ${ }^{19}$ compares first-void with midstream urine sampling and finds similar diagnostic rates for Chlamydia trachomatis testing. Based on this study's findings, we can dispense with the inconvenient practice of collecting first-void urine for Chlamydia testing.

In an analysis with implications for developing a learning health care system, Delaney and colleagues ${ }^{20}$ examine options and evaluate the adoption of a prototype for conducting clinical research using electronic health records in dispersed practices in practice-based research networks. This cutting-edge research highlights both the challenges and opportunities for linking existing electronic clinical data for research.

The effect of facilitation of practice change is examined in a systematic review by Baskerville et al. ${ }^{21}$ In addition to finding robust evidence for overall effectiveness, a meta-regression analysis found that tailoring intervention intensity and the number of intervention practices per facilitator modified the effect of facilitation on adoption of evidence-based guidelines.

In an essay a family physician describes the experience of caring for a Kenyan woman in obstructed labor, which causes him to reflect on arrogance, crosscultural practice, and the nature of science. ${ }^{22}$

Please join the ongoing discussion of these articles and their implications at http://www.AnnFamMed.org.

\section{References}

1. Lin EHB, Von Korff M, Ciechanowski $P$, et al. Treatment adjustment and medication adherence for complex patients with diabetes, heart disease, and depression: a randomized controlled trial. Ann Fam Med. 2012;10(1):6-14.

2. Bogner HR, Morales KH, de Vries HF, Cappola AR. Integrated management of type 2 diabetes mellitus and depression treatment to improve medication adherence: a randomized controlled trial. Ann Fam Med. 2012;10(1):15-22.

3. Morris DW, Budhwar N, Husain M, et al. Depression treatment in patients with general medical conditions: results from the CO-MED trial. Ann Fam Med. 2012;10(1):23-33.

4. Bayliss EA. Simplifying care for complex patients. Ann Fam Med. 2012;10(1):3-5.

5. Fortin M, Bravo G, Hudon C, Lapointe L, Dubois MF, Almirall J. Psychological distress and multimorbidity in primary care. Ann Fam Med. 2006;4(5):417-422. 
6. Fortin M, Bravo G, Hudon C, Vanasse A, Lapointe L. Prevalence of multimorbidity among adults seen in family practice. Ann Fam Med. 2005;3(3):223-228.

7. Stange KC. The paradox of the parts and the whole in understanding and improving general practice. Int J Qual Health Care. 2002;14(4):267-268

8. Stange KC. The problem of fragmentation and the need for integrative solutions. Ann Fam Med. 2009;7(2):100-103.

9. Fortin M, Lapointe L, Hudon C, Vanasse A. Multimorbidity is common to family practice: is it commonly researched? Can Fam Physician. 2005;51:244-245.

10. Mercer SW, Smith SM, Wyke S, O'Dowd T, Watt GC. Multimorbidity in primary care: developing the research agenda. Fam Pract. 2009;26(2):79-80.

11. Fortin M, Soubhi $H$, Hudon C, Bayliss EA, van den Akker M. Multimorbidity's many challenges. BMJ. 2007;334(7602):1016-1017.

12. Valderas JM, Starfield B, Sibbald B, Salisbury C, Roland M. Defining comorbidity: implications for understanding health and health services. Ann Fam Med. 2009;7(4):357-363.

13. Rich EC, Lipson D, Libersky J, Peikes DN, Parchman ML. Organizing care for complex patients in the patient-centered medical home. Ann Fam Med. 2012;10(1):60-62.

14. Agency for Healthcare Research and Quality (AHRQ). Coordinating care for adults with complex care needs in the patientcentered medical home: challenges and solutions. 2011. http:// pcmh.ahrq.gov/portal/server.pt/community/pcmh__home/1483/ PCMH_Home_Papers\%20Briefs\%20and\%200the\%20Resources_v2.
15. Stange KC. A science of connectedness. Ann Fam Med. 2009;7(5): 387-395.

16. Stange KC. The generalist approach. Ann Fam Med. 2009;7(3): 198-203.

17. Jerant A, Fenton JJ, Franks P. Primary care attributes and mortality: a national person-level study. Ann Fam Med. 2012;10(1):34-41.

18. Hoebert JM, Souverein PC, Mantel-Teeuwisse AK, Leufkens HGM, van Dijk L. Reimbursement restriction and moderate decrease in benzodiazepine use in general practice. Ann Fam Med. 2012;10(1):42-49.

19. Mangin D, Murdoch D, Wells JE, et al. Chlamydia trachomatis testing sensitivity in midstream compared with first-void urine specimens. Ann Fam Med. 2012;10(1):50-53.

20. Delaney BC, Peterson KA, Speedie S, Taweel A, Arvanitis TN, Hobbs FDR. Envisioning a learning health care system: the electronic Primary Care Research Network, a case study. Ann Fam Med. 2012;10(1):54-59.

21. Baskerville NB, Liddy C, Hogg W. Systematic review and metaanalysis of practice facilitation within primary care settings. Ann Fam Med. 2012;10(1):63-74.

22. Pust RE. Indication. Ann Fam Med. 2012;10(1):75-78.

\title{
EDITORIAL
}

\section{Simplifying Care for Complex Patients}

\author{
Elizabeth A. Bayliss, MD, MSPH, Associate Editor \\ Institute for Health Research, Kaiser Permanente, Denver, Colorado
}

Ann Fam Med 2012;10:3-5. doi:10.1370/afm.1352.

$\mathrm{T}$ The challenge of delivering patient-centered care to complex patient populations is to provide the right care for the right person at the right time. Our ability to do so is contingent upon accurately identifying specific populations, assessing their care needs, and developing models to meet those needs.

In this issue of the Annals, 3 investigations illustrate

Conflicts of interest: author reports none.

\section{CORRESPONDING ADDRESS}

Elizabeth A. Bayliss, MD, MSPH

Institute for Health Research

Kaiser Permanente

10065 E Harvard Ave, Ste 300

Denver, CO 80231-5968

Elizabeth.Bayliss@KP.org the value of targeting clinician, patient, and system behavior as interrelated paths to improvement in health outcomes in complex patient populationsspecifically populations with depression plus other chronic conditions.

These articles present evidence from randomized controlled trials to inform different aspects of caring for patients with depression plus other comorbid conditions: Lin et al describe the positive effect of a team-based care intervention on initiation and adjustment of pharmacotherapy for persons with depression plus diabetes and/or coronary heart disease, ${ }_{1}^{1}$ Bogner et al use integration care managers to improve medication adherence and subsequent disease outcomes for persons with depression and diabetes, ${ }^{2}$ and Morris et al show that the effectiveness and side-effect profiles of different antidepressant medication regimens are 